\title{
KANT E A SECULARIZAÇÃO DA ESCATOLOGIA CRISTÃ
}

\author{
KANT AND THE SECULARIZATION OF CHRISTIAN ESCHATOLOGY
}

Marcelo da Costa Maciel*

\section{RESUMO}

Este artigo pretende apontar as analogias e diferenças fundamentais entre a filosofia de Kant e a doutrina cristã (especialmente aquela formulada por Santo Agostinho) com relação à célebre discussão a respeito do mal e a visão escatológica da história humana. Sugere-se que a influência exercida pelo pensamento de Rousseau contribuiu para que as ideias kantianas se distinguissem da visão cristã tradicional, exprimindo a mudança na estrutura de fundo em que se manifesta o pensamento genuinamente moderno. Demonstra-se que a reflexão kantiana sobre o mal, bem como sua filosofia da história, são marcadas pela perspectiva da imanência, buscando no próprio homem a origem do mal e nutrindo uma esperança de redenção que nada tem de transcendente, mas realiza-se na história por meio da ação humana. $\mathrm{O}$ artigo conclui que, enquanto Agostinho, com sua ideia da "queda" e da consequente corrupção da natureza humana, ressalta a noção cristã de redenção, Kant traduz tal noção pela concepção secularizada da perfeição moral do homem, construída ao longo de um processo de aprendizado da razão, que confere à história humana o caráter de um crescente esclarecimento do conteúdo e da forma da lei moral.

PALAVRAS-CHAVE: Problema do mal. Escatologia cristã. Filosofia kantiana da história. Secularização. Imanência.

\begin{abstract}
The article intends to point out analogies and fundamental differences between Kant's philosophy and Christian doctrine (especially in augustinian version) with respect to the famous discussion of evil and the eschatological vision of human history. It is suggested that the influence exerted by the thought of Rousseau contributed to making Kant's ideas distinguishable from the traditional Christian vision, expressing the change in the underlying structure in which the genuinely modern thought arose. One demonstrates that Kant's reflection on evil, as well as his philosophy of history, are marked by the prospect of immanence, seeking the origin of evil in the man himself and nurturing a hope of redemption, which is not transcendent, but takes place in history through human action. The article concludes that, while Augustine, with his idea of the "fall" and the resulting corruption of human nature, emphasizes the Christian notion of redemption, Kant replaces this notion by a secularized conception of moral perfection, built along a learning process of reason, which gives human history the character of an increasing clarification of the content and form of the moral law.
\end{abstract}

KEYWORDS: Problem of evil. Christian eschatology. Kant's philosophy of history. Secularization. Immanence.

\footnotetext{
* Doutorado em Ciência Política. Professor Associado I da Universidade Federal Rural do RJ. E-mail: marcelocmaciel@bol.com.br.
}

Sapere aude - Belo Horizonte, v. 11 - n. 21, p. 194-206, Jan./Jun. 2020 - ISSN: 2177-6342 


\section{INTRODUÇÃO}

Ao pretendermos discorrer sobre as reflexões de Kant a respeito da religião e da moral, é obrigatório que reconheçamos, desde o início, a crucial influência exercida sobre ele pelo pensamento de Rousseau, sobretudo a influência da obra Emílio ou da educação, que, de acordo com o que nos diz Cassirer (1999, p. 71), era um dos livros preferidos de Kant. A leitura de algumas obras de Kant (como Começo conjectural da história humana e A religião dentro dos limites da simples razão, publicadas respectivamente em 1786 e 1793) é suficiente para constatarmos a afirmação de Cassirer e identificarmos na "profissão de fé do vigário saboiano" (ROUSSEAU, 1979, p. 223-268) a inspiração para a definição kantiana da religião, que a vê como fundada na moral, e não como o fundamento desta.

Precedido por Rousseau (mas também por Locke), Kant tomou para si a tarefa de examinar a possível correspondência entre preceitos éticos universais (uma vez que decorrentes diretamente da pura razão) e preceitos acolhidos pela revelação, para os quais a filosofia cristã vinha, desde o seu nascimento, tentando dar uma demonstração cabal e definitiva. Esse exame resultará em uma nova forma de acesso à ideia de Deus, bem como em uma nova modalidade de prova da sua existência: a ideia de Deus tornar-se-á evidente pela via da razão prática (e não mais pela razão especulativa), e a prova de sua existência será apresentada como um postulado moral.

Todavia, essa espécie de guinada moral na reflexão kantiana sobre Deus não foi realizada antes de sua filosofia crítica ter passado em revista todos os esforços da metafísica em dar provas da existência de Deus. Não cabe aqui reconstituir a crítica radical a que Kant submete toda a teologia que parte da razão especulativa, mas apenas registrar que ele toma a sério todos os argumentos que, desde Santo Anselmo, passando por São Tomás de Aquino e Descartes, pretenderam formular alguma espécie de prova para a existência de Deus. Kant recoloca e desenvolve o chamado argumento ontológico e chega até seus limites a partir da consciência dos próprios limites de uma razão que se examina a si mesma. Quanto aos argumentos cosmológico e teleológico, Kant acrescenta a noção de um Universo como um organismo funcionando por si mesmo e dotado de uma dinâmica imanente, mas tenta preservar a ideia de Deus, agora não mais como o arquiteto do mundo (como queriam os defensores de um desígnio providencial), mas como o criador da matéria. O fato é que a investigação crítica de Kant não reconhece como válida nenhuma prova da existência de Deus à luz da razão especulativa. A circunscrição de todo conhecimento ao domínio da experiência 
humana faz com que o conhecimento seja representativo dessa experiência, enquanto a realidade mesma (ou coisa-em-si) necessariamente nos escapa. Assim sendo, Deus jamais poderá ser objeto do conhecimento humano. Tal constatação traz consigo uma consequência desconcertante e cheia de implicações morais: o reconhecimento de que a afirmação "Deus existe" não contém qualquer conhecimento verdadeiro a respeito da entidade transcendente a que ela se refere.

Convencido de que não é pela metafísica que a razão poderá dar justificativa satisfatória para a fé em Deus, Kant, leitor de Rousseau, empreenderá a tarefa a que aludimos acima: demonstrar que a existência de Deus, embora indemonstrável, deve ser postulada e que essa exigência decorre da razão prática, pois é condição para a plena realização da lei moral. Isso porque a lei moral consiste em um dever que, sendo um bem em si mesmo, se impõe ao agente moral de modo incondicional e ao qual ele deve sacrificar todo desejo egoístico. A ideia de Deus, embora dela não possamos ter qualquer conhecimento, é a fundamentação racional mais perfeita da obrigatoriedade desse dever. Nesse sentido, Deus deve ser tomado como aquele que pronuncia o imperativo categórico; é ele quem declara o "tu deves" que cada homem ouve em sua própria consciência.

Mas, poderíamos perguntar, por que precisamos supor Deus como aquele que fala em nossa consciência, se é exclusivamente por meio da própria razão que chegamos a saber o conteúdo do dever moral? Para responder a essa questão, Kant recorda que a obediência à lei moral, além de consistir no supremo bem, deve ser vista como a própria felicidade, sem o quê o agente preferiria dar vazão aos apetites e inclinações de sua natureza animal ao invés de submetê-la livremente à sua natureza moral. É a identificação da perfeita moralidade com a máxima felicidade que torna imperioso o cumprimento da lei moral e permite que ela seja racionalmente vista como o bem supremo. Contudo, sendo supremo, tal bem não pode realizar-se plenamente no curso de uma existência finita (ao longo da qual o indivíduo, visando à execução da lei moral, precisa superar os três graus de propensão para o mal presentes na natureza humana, a saber, a fraqueza, a impureza e a perversidade do coração humano), daí decorrendo a necessidade de postularmos a imortalidade da alma e, com ela, a certeza de uma vida futura em que o bem supremo, enquanto coincidência do dever com a beatitude, seja finalmente alcançado. Por outro lado, o bem supremo, assim definido, traz outra exigência: sua realização, não sendo possível na ordem atual, só é possível se existir um poder supremo capaz de garantir a harmonização da pura moralidade com a plena felicidade. Esse poder deve ser capaz de avaliar a intenção e valor moral das condutas, atribuindo a seus 
agentes a recompensa devida na forma de uma felicidade proporcional à moralidade das condutas, devendo, por isso mesmo, ser, além de onipotente, absolutamente sábio, bom e justo. Enfim, só podemos atribuir esse poder a um ser que contém em si toda a perfeição, e a este ser devemos chamar Deus.

Assim sendo, se a razão pura não pode nos persuadir de que Deus existe, a razão prática nos persuade de que ele deve existir e, dessa forma, a mesma razão que torna obrigatória a obediência à lei moral fundamenta a adesão a uma verdade que, antes, carecia de fundamento racional e era acolhida simplesmente pela fé na revelação. Somos levados a crer na existência de Deus pela via do raciocínio, mas a compreensão do ser desse Deus se situa para além de qualquer raciocínio. Tal compreensão repousa no domínio próprio da fé: uma fé situada, por assim dizer, nos confins da razão. Dar à prova da existência de Deus o atributo de um postulado moral significa dizer que a existência de Deus fica provada para o homem e somente para o homem, sendo a necessária condição de possibilidade de sua ação moral. De resto, esta conclusão é coerente com toda a filosofia crítica kantiana, que, ao situar na própria razão os fundamentos e limites do nosso entendimento, vincula inexoravelmente o entendimento ao sujeito humano e às suas condições.

Todavia, a fundamentação racional da fé na existência de Deus e na imortalidade da alma não conduz automaticamente à ação moral. Esta, por definição, é um ato da vontade humana, já que o homem é e deve ser representado como ser livre. Nesse ponto, a reflexão de Kant depara-se com a célebre discussão a respeito do mal e de sua origem, discussão cara à filosofia cristã, e que será abordada a seguir.

\section{KANT E O PROBLEMA DO MAL}

Podem-se perceber na solução de Kant ao problema da teodiceia analogias fundamentais com a doutrina do Santo Agostinho, particularmente com a visão escatológica de Agostinho acerca da história humana. Porém, as ideias de Kant a esse respeito, também aqui fortemente impactadas pelo pensamento de Rousseau, exprimem com agudeza a mudança na estrutura de fundo em que se manifesta o pensamento moderno. Brotando do cerne de uma era secular, a reflexão kantiana sobre o problema da teodiceia, bem como sua filosofia da história, serão marcadas pela perspectiva da imanência, buscando no próprio homem a origem do mal que ele pratica e nutrindo uma esperança de redenção que nada tem de transcendente, mas realiza-se na história por meio da ação humana. 
Em sua obra $A$ religião dentro dos limites da simples razão, Kant elabora uma antropologia filosófica na qual uma propensão para o mal é vista como inscrita na natureza humana. Essa propensão é expressa filosoficamente pelo conceito de "mal radical" (KANT, 1974). Convém, contudo, salientar que, com isto, Kant não quer afirmar que o homem seja mau por natureza. Uma afirmação como esta contradiria o próprio conceito do homem, que é determinado unicamente por sua vontade livre, e não por quaisquer propensões encontradas em sua natureza. Não se deve afirmar que o homem seja nem bom nem mau por natureza, mas que sua natureza contém disposições que lhe permitem querer tanto o bem quanto o mal, e que a propensão para o mal designa a satisfação natural que o indivíduo encontra ao desfrutar de tudo aquilo que lhe é agradável ou que atende aos seus desejos. Esta, como qualquer propensão, é uma tendência que existe em potência na natureza do homem, mas que só se torna uma inclinação quando o indivíduo realiza o desejo por um ato de arbítrio. Segundo Kant, não se pode culpar Deus pela simples presença de uma propensão para o mal em nossa natureza. Em primeiro lugar, porque ela não determina a prática do mal, o que estará na dependência do arbítrio exclusivamente humano e, em segundo lugar, porque esta mesma propensão é, na verdade, providencial por proporcionar ocasião para o aprimoramento do homem pelo próprio homem que, ao impedir que a propensão se torne inclinação, supera a sua natureza animal e a ela acrescenta uma natureza moral fundada sobre a noção de responsabilidade.

Aqui podemos confrontar as ideias de Kant sobre o estatuto do mal no homem com as de Rousseau e de Santo Agostinho. Assim como estes dois pensadores, Kant está interessado em realizar uma espécie de justificação de Deus, isentando-o da imputabilidade da origem do mal praticado pelo homem. Tanto em Rousseau quanto em Santo Agostinho o mal tem origem no próprio homem, mas não como determinação de sua natureza, o que levaria a isentá-lo de toda culpa, pois ele não poderia ser responsável por determinações dispostas em sua natureza pelo Criador. Porém, enquanto em Santo Agostinho a liberdade do homem (em si mesma uma dádiva, pois que o torna imagem e semelhança de Deus) é responsável pela corrupção da própria vontade, tornando-a uma má vontade, isto é, uma vontade de praticar o mal, em Rousseau a perfectibilidade da natureza humana é também o que possibilita que o homem se corrompa a si próprio, mas, apresentando uma visão até então inaudita, Rousseau imputa a responsabilidade pela emergência do mal não ao indivíduo, mas à sociedade. Como diz na abertura do Emílio: "Tudo é certo em saindo das mãos do Autor das coisas, tudo degenera nas mãos do homem" (ROUSSEAU, 1979, p. 11). Assim, a novidade da solução de 
Rousseau para o problema da teodiceia consistiu em deslocá-lo do campo da metafísica e da teologia para o da ética e da política. Tal maneira de recolocar o problema exerceu fascínio sobre Kant, que assim se refere a Rousseau em sua obra Começo conjectural da história humana:

Em seus escritos sobre a Influência das ciências e sobre a Desigualdade entre os homens, ele mostra, com justeza, o inevitável antagonismo entre a cultura e a natureza do gênero humano como espécie física, no qual todo o indivíduo deve realizar plenamente a sua destinação; mas, em Emílio, Contrato Social e outros textos, ele busca resolver um problema ainda mais difícil: saber como a cultura deve progredir para desenvolver as disposições da humanidade, como espécie moral, conforme a sua destinação, de sorte que esta última não se oponha mais à primeira, à espécie natural. (KANT, 2010, p. 25-26).

Dessa forma, Kant e Rousseau aproximam-se de Santo Agostinho, por um lado, ao identificarem uma disposição para o bem na natureza do homem tal como saída das mãos do Criador (que, como disposição, é somente uma capacidade, só se tornando efetiva pelo uso da liberdade) e, por outro, ao considerarem o mal original obra exclusivamente humana e, assim, também dependente do uso da liberdade. Contudo, com relação ao mal perpetrado presentemente pelo homem, os dois pensadores do século XVIII têm explicações que divergem bastante da visão agostiniana. Para o Bispo de Hipona, o pecado original, pelo qual o mal entrou no mundo, marcou de forma indelével a própria constituição natural do homem, originando uma verdadeira inclinação para a prática do mal decorrente de uma vontade corrompida. A corrupção experimentada por nossos antepassados é transmitida a cada novo homem vinculado a Adão pela geração. Deus cria (no sentido bíblico de uma criação ex nihilo) apenas o primeiro homem. A partir daí, os homens são gerados de outros homens, que transmitem de geração a geração as características fundamentais de uma natureza para sempre enfraquecida pelo pecado dos primeiros pais. Só Adão experimentou o estado original de inocência; todos os demais homens já chegam a este mundo com uma inclinação natural para o mal, isto é, para o desvio com relação à boa vontade, precisando buscar, por uma decisão autônoma, a ajuda da graça divina, sem a qual o homem não tem condições de superar as limitações (herdadas) de sua natureza e reencontrar sua origem, ou seja, a condição segundo a qual foi concebido como ideia de Deus.

Um primeiro afastamento efetuado por Kant com relação a essa explicação repousa na sua rejeição da ideia de herança, pois "as ações do arbítrio nada de hereditário trazem consigo" (KANT, 2010, p. 38). Assim sendo, a total responsabilidade pelo mal praticado por 
um homem, hoje, deve ser atribuída a este mesmo homem, mais precisamente ao abuso de sua razão, sendo de esperar que, colocados na posição de nossos antepassados, muito provavelmente teríamos experimentado a mesma "queda", não submetendo rigorosamente nosso querer à nossa razão. E mais: podemos dizer que a culpa dos homens de hoje é ainda maior, pois eles podem beneficiar-se do progresso da razão, como aprendizado acumulado ao longo da história cultural humana, o que não era possível nos primórdios desta história. Já a visão de Rousseau concorda com a de Kant, ao recusar que a corrupção do homem tenha atingido o âmago de sua natureza e que seja transmitida a cada novo indivíduo que nasce. Nas palavras de Jean Starobinski (2011, p. 24-34):

\begin{abstract}
Ora, se a queda é nossa obra, se é um incidente da história humana, é preciso admitir que o homem não está naturalmente condenado a viver na desconfiança, na opacidade e nos vícios que as escoltam [...] A essência do homem não está comprometida, mas apenas sua situação histórica [...] deve-se admitir que o homem é culpado e carrega a culpa de todo o mal que fez a si mesmo; mas, por outro lado, na medida em que o homem não deixa de ser um filho da natureza, ele conserva uma inocência indestrutível.
\end{abstract}

Contudo, a perspectiva de Rousseau se distingue da de Kant ao enfatizar a sociedade humana, e não mais o indivíduo isolado, como sujeito da responsabilidade pelo mal. Com efeito, Kant, na sua conjectura sobre o início da história humana, descreve um contexto em que ainda não há sociedade, apesar de já haver os primórdios da cultura (como relação do homem com a natureza mediada pela liberdade e pela inventividade humanas), e é nesse contexto primordial que o mal já se instaura como obra humana. Fazendo abstração da ação específica que a sociedade enquanto tal pode exercer sobre o uso que o homem faz de sua razão, Kant mostra que o indivíduo (cuja natureza não o condena à prática do mal, mas comporta uma propensão que o torna capaz disso) pode, por um uso equivocado de sua liberdade, transformar tal propensão em máxima de sua conduta, invertendo a ordem da lei moral e, assim, sendo o único responsável pelo mal que ele mesmo pratica. Já em Rousseau, o estado natural não deve ser interpretado como o estado original da história humana, mas como abstração cujo fim é delinear as condições elementares do ser humano na sua integridade natural e, portanto, ainda sem a experiência da vida social. Em seu estado natural, o ser humano carrega em si infinitas potencialidades, e é isto que Rousseau quer exprimir com a ideia de perfectibilidade. Tais potencialidades ganham forma e direção somente dentro do agregado humano constituído das relações que os homens, enquanto sociáveis, são capazes de estabelecer entre si. Esse agregado é como um novo ser, em si mesmo distinto dos indivíduos 
tomados isoladamente, e isto traz consequências profundas sobre as condições da ação dos próprios indivíduos. É claro que todo mal, em sendo obra da vontade, é obra humana e, por isso, o homem é seu autor. Porém, a peculiaridade do pensamento de Rousseau reside no seu original caráter sociológico, sublinhado, não por acaso, por Durkheim, que vira em Rousseau um dos fundadores da moderna ciência da sociedade. Essa interpretação de Durkheim parece justificar-se quando lemos no Emílio: "É preciso estudar a sociedade pelos homens, e os homens pela sociedade: os que quiserem tratar separadamente da política e da moral nunca entenderão nada de nenhuma das duas." (ROUSSEAU, 1979, p. 196). Portanto, para Rousseau, não se pode fazer abstração da relação entre o homem e a sociedade na explicação da origem do mal criado pelo próprio homem, mas, citando novamente Starobinski (2011, p. 35), "repelido para a periferia do ser, rechaçado para o mundo da relação, o mal não terá o mesmo estatuto ontológico que a bondade natural do homem".

\section{A Filosofia KANTIANA DA HISTÓRIA E A SECULARIZAÇÃo DA ESCATOLOGIA CRISTÃ}

Retornando a Kant, outro aspecto em que seu pensamento difere da doutrina agostiniana diz respeito à concepção da história e, dentro desta, à noção de progresso. Santo Agostinho, interpretando as expectativas escatológicas contidas no Novo Testamento, elabora uma visão inovadora, que pode ser considerada a primeira filosofia da história na tradição ocidental. O não cumprimento imediato da escatologia universal trouxe para a filosofia cristã a necessidade de apresentar um sentido para o mundo e para a continuidade deste ao longo do tempo. Nesse sentido, a dogmática cristã falará de uma escatologia individual e de um juízo particular, enquanto a humanidade espera pela consumação dos séculos e pelo Juízo Final, que não se pode dizer quando ocorrerão. Diante desse cenário, Santo Agostinho formulará, com base em uma minuciosa leitura das Escrituras, uma descrição da história humana que remontará à Criação narrada pelo Livro do Gênesis e terá como clímax a realização dos acontecimentos escatológicos descritos pelo Livro do Apocalipse, isto é, o fim do mundo, a segunda vinda de Cristo, o Juízo Final, a restauração da Terra para os justos e a fundação nela do Reino Eterno de Deus. Enquanto tais promessas não se realizam, a humanidade viveria um tempo em que os santos têm de conviver com os pecadores e, assim, o reino espiritual daqueles que vivem de acordo com o Evangelho (a "cidade de Deus") tem, inevitavelmente, de existir sob reinos e poderes meramente mundanos, que formariam a "cidade terrena" 
(também chamada "cidade do homem" ou "cidade do pecado") (AGOSTINHO, 2011). Da narrativa bíblica, portanto, depreende-se o sentido da existência do mundo e da história humana, e é dela que o indivíduo deve extrair os critérios pelos quais pautará seu comportamento e preparar-se-á para a escatologia pessoal (que ocorrerá com sua morte) e para a universal (que consistirá no fim do mundo). De todo modo, o indivíduo deve esperar uma recompensa para o seu comportamento neste mundo que não consiste em nenhuma forma de felicidade terrena. O cristão autêntico (cuja vocação é viver neste mundo como se não pertencesse a ele) anseia pela redenção, e esta se realiza de forma sobrenatural, exigindo seu esforço por merecer, mas advindo a ele por ação da graça e do poder de Deus.

Podemos identificar analogias estruturais entre a escatologia cristã e visão kantiana da história, mas desde logo precisamos salientar que, em Kant, a noção cristã de redenção se traduz como a perfeição moral do homem. Tal perfeição, cuja fisionomia coletiva é expressa pelo conceito de "civilização", deve ser encarada pela humanidade como sua meta e ponto culminante de sua história: “o momento em que a arte, atingindo a perfeição, se torna de novo natureza, que é a meta derradeira da destinação moral da espécie humana” (KANT, 2010, p. 29). Vê-se que a escatologia moral de Kant, almejando um tipo de florescimento humano a ser alcançado aqui neste mundo e por obra da vontade dos próprios homens, corresponde a uma visão secularizada da escatologia cristã, embora, como vimos, Kant não deixe de atribuir a Deus papel crucial no aperfeiçoamento moral do homem. Acontece que, no esquema kantiano, é por meio da própria razão que o homem é levado a postular a existência de Deus, e tal postulado dá sentido à lei moral que o homem descobre em si mesmo, o que é bem diferente da crença em uma revelação divina que dá a conhecer ao homem um ideal de moralidade, bem como da crença na necessidade da ação da graça para a realização plena dessa moralidade. Nesse sentido, o pensamento de Kant busca dar conta daqueles perenes anseios do homem por plenitude e sentido de que fala Charles Taylor em sua obra Uma era secular (2010). Situando-se no apogeu do pensamento moderno, a obra de Kant reconhece a existência do transcendente, mas declara não ser possível ao homem conhecê-lo, e descobre no próprio homem uma dimensão transcendental à qual se tem acesso pela pura razão e na qual se funda a moral: uma moral absoluta e universal, capaz de conferir unidade ao gênero humano e sentido à sua trajetória sobre a Terra.

Cabe, agora, contrastar as concepções kantianas a respeito da história e da civilização com o pensamento de Rousseau, que experimentou um verdadeiro isolamento no contexto intelectual de sua época, em parte devido à visão destoante que apresenta em um século 
marcado por uma profissão de fé na razão como instrumento necessário e suficiente para o progresso moral do homem e o aperfeiçoamento das instituições sociais. É certo que, em Do contrato social (cujo subtítulo é Princípios do direito político), Rousseau concebe um modo de constituição da sociedade política construído pela ação de homens livres, não depravados pela corrupção humana historicamente produzida. Pode-se tomar essa obra como um projeto de sociedade ideal, na qual as convenções não seriam como máscaras a ocultar a verdadeira essência humana e na qual o ser social do homem pudesse reencontrar o seu ser natural. Acontece que a sociedade descrita no Contrato não é apresentada em linha de continuidade com a narrativa histórica que Rousseau desenvolve no Discurso sobre a origem e os fundamentos da desigualdade entre os homens. No Discurso, Rousseau enfatiza os malefícios engendrados na e pela sociedade, malefícios que instauram uma opacidade entre os homens e impedem que estes tenham acesso imediato à natureza de seu ser pois sua atenção é dirigida para o mundo exterior, com seus bens materiais e convenções artificiais. Tal opacidade e tal alienação avolumam-se quanto mais civilizada, isto é, artificiosa se torna a sociedade humana. Efetivamente, Rousseau não aponta um meio pelo qual os homens corrompidos, não em sua natureza, mas na representação equivocada que fazem de si mesmos e à qual se veem agarrados como se fosse sua natureza, possam interromper esse processo (que nada mais é senão o desenvolvimento da civilização) e recuperar o verdadeiro conhecimento de si mesmos, desvencilhando-se do vício do amor-próprio e deixando falar o natural amor de si. A educação, certamente, seria uma oportunidade de formar o homem social em consonância com o homem natural, mas jamais a educação até então praticada, que só reproduz a alienação do homem e a perversão da ordem da natureza. O programa educativo exposto no Emílio deve ser visto como uma crítica desencantada das noções socialmente construídas que norteiam as práticas educacionais; nele vê-se o pessimismo de Rousseau quanto à civilização, e não uma crença na educação como meio de aperfeiçoamento do homem. O mesmo tom impregna tanto o Discurso sobre as ciências e as artes (seu primeiro texto filosófico) quanto os escritos autobiográficos do fim de sua vida.

Diante disso, constatamos que Rousseau considerou o homem autor da sua própria corrupção, mas uma corrupção gerada na história enquanto avança o "cortejo de vícios" da sociedade humana (ROUSSEAU, 2019). De fato, ele não acalentaria motivos para crer que a história humana caminhasse para um patamar melhor, vale dizer, mais consentâneo à natureza. Contudo, na obra Do contrato social, ele escreve como pensador político, e o pensador político pode permitir-se uma espécie de aposta que o examinador da natureza 
humana e da história não pode. O pensador político é mais comprometido com a postulação do dever ser do que com o rigor na compreensão do que é. Assim como Kant, que, reconhecendo a impossibilidade de apresentar uma prova da existência de Deus dentro dos limites da razão, postula argumentativamente a necessidade moral de crer na sua existência, Rousseau postula que uma redenção deve ser possível e, por isso, propõe o seu projeto político, a ser construído com base em um autêntico contrato social. Vale ressaltar que tal redenção, exclusivamente secular, é realizada na história; a aposta no florescimento de uma nova humanidade é tarefa dirigida aos homens e projetada para este mundo, pois, como ressalta Cassirer (1999, p. 74), “a redenção espera em vão por ajuda exterior. Nenhum Deus nos pode enviá-la; o homem deve sim se transformar no seu próprio salvador e, no sentido ético, no seu criador".

Quanto a Kant, tomemos como ponto de partida a sua concepção da história da humanidade como a história da razão, interpretada como um contínuo progresso para um estado melhor. Ao longo desse progresso, o homem tem a oportunidade de empreender um aprendizado no qual toma posse, por assim dizer, da própria razão, que sempre esteve nele, já que é uma de suas faculdades naturais, mas que, aos poucos, vai sendo convertida pelo próprio homem em guia único de seu pensamento e ação. Esse processo é paulatino porque exige que os homens se desvencilhem de preconceitos e convenções nascidos da cultura, e não submetidos ao crivo exclusivo da razão. A cultura, como reino da arte humana, é o terreno em que o homem, como único ser mortal livre, emancipa-se da natureza. Segundo Kant, tal emancipação refere-se à condição de animalidade do homem e visa ao nascimento de seu ser moral. Portanto, também para Kant, vale o que foi dito acima a propósito de Rousseau: o homem, no sentido moral, é criador de si mesmo.

Todavia, refletindo o espírito predominante em seu século, Kant revela um otimismo com relação ao processo cultural. Ele sabe que as formas de sociedade e as convenções até então fabricadas pelo homem estão longe de corporificarem o império da razão e, por extensão, da lei moral, mas vê o homem de seu tempo como aquele que tem condições objetivas para atingir o que ele chamou de "maioridade" e, com ela, realizar um verdadeiro "esclarecimento", o que implica uma autêntica crítica da cultura com vistas à construção de uma "civilização" como projeto universal em que formas culturais definitivas correspondam aos imperativos da lei moral. 


\section{CONSIDERAÇÕES FINAIS}

Ao finalizar estas breves reflexões sobre religião e moral em Kant, não é possível deixar de sublinhar que, para ele, a razão humana, quando sonda os seus próprios confins, encontra necessariamente Deus, bem como a idea Christi como personificação do ideal da perfeita moralidade e o próprio Cristo histórico como Redentor.

Isto porque, como vimos, a fé na existência de um ser perfeito e de uma vida futura está implicada na adesão à lei moral, uma vez que o bem supremo, representado pela coincidência da perfeita moralidade com a máxima felicidade, só pode ser realizado após a superação de todos os limites com os quais temos de lutar na nossa existência terrena e como recompensa justa avaliada pela sabedoria de um ser infalível.

Além disso, a ideia de Cristo, como homem que realiza plenamente o ideal da moralidade, é absolutamente útil, pois ilumina a nossa razão ética, levando-nos ao esforço contínuo por alcançar, já aqui nesta existência, a perfeição moral, que é amar o dever por reconhecer nele o bem supremo.

E, por fim, mesmo tendo razões para crer que não há garantias para a consecução da plena moralidade neste mundo, devemos, ainda assim, envidar o máximo esforço para atingila, o que concretamente se traduz pelo propósito sincero e consequente de merecer ser feliz, em lugar do desejo de ser feliz. Somente aquele que pauta sua conduta por tal critério, salienta Kant, pode esperar que a redenção chegue na forma do gozo infinito da beatitude, pois, para além do domínio da razão humana, só há o domínio da transcendência, diante da qual o homem se cala e espera, assentado em uma fé pura, a ação redentora do Cristo histórico, o próprio Deus feito homem.

\section{REFERÊNCIAS}

AGOstinHO, Santo. Cidade de Deus. Petrópolis: Vozes, 2011.

CASSIRER, Ernest. A questão Jean-Jacques Rousseau. São Paulo: UNESP, 1999.

KANT, Immanuel. A religião dentro dos limites da simples razão. São Paulo: Abril Cultural, 1974. (Os Pensadores).

KANT, Immanuel. Começo conjectural da história humana. São Paulo: UNESP, 2010. 
ROUSSEAU, Jean-Jacques. Do contrato social ou princípios do direito político. São Paulo: Nova Cultural, 1991a. (Os Pensadores).

ROUSSEAU, Jean-Jacques. Discurso sobre a origem e os fundamentos da desigualdade entre os homens. São Paulo: Nova Cultural, 1991b. (Os Pensadores).

ROUSSEAU, Jean-Jacques. Discurso sobre as ciências e as artes. Lisboa: Edições 70, 2019.

ROUSSEAU, Jean-Jacques. Emílio ou da educação. São Paulo: Difel, 1979.

STAROBINSKI, Jean. Jean-Jacques Rousseau: a transparência e o obstáculo. São Paulo: Companhia das Letras, 2011.

TAYLOR, Charles. Uma era secular. São Leopoldo, RS: UNISINOS, 2010. 